\title{
Prostate Imaging-Reporting and Data System
}

National Cancer Institute

\section{Source}

National Cancer Institute. Prostate Imaging-Reporting and Data System. NCI Thesaurus. Code C116385.

A structured reporting scheme for multiparametric prostate cancer imaging and diagnosis. Prostate images are obtained using multiple MRI techniques including T2 weighted images, a dynamic contrast-enhanced study (DCE), diffusion weighted imaging (DWI), and possibly spectroscopy (MRS). Each lesion receives a score from 1 to 5 for each individual imaging parameter, as well as an overall 1-5 grading score reflecting the likelihood of clinically significant cancer, with 1 being most probably benign and 5 being highly suspicious of malignancy. 